\title{
Taxonomias e Consideraçóes Metodológicas sobre Testes de Usabilidade em Sistemas Interativos Mulltimídia
}

\author{
(Taxonomies and Methodological Considerations Qn Usability Testing in \\ Interactive Multimedia Systems)
}

\author{
HERNANE B. B. PEREIRA \\ (Universidade Estadual de Feira de Santana — UEFS) \\ JOSEP M ${ }^{\mathrm{a}}$ MONGUET FIERRO \\ (Universistat Politécnica de Catalunya — UPC)
}

\begin{abstract}
RESUMEN: Neste artigo apresentarnos um estudo que contribui corn conceitos e taxonomias para o desenvolvimento de urna metodologia de estruturaçdo, irnplantaçdo e aplica çao de Testes de Usabilidade ern sisternas interativos multimídia para a forma çdo a distáncia. O estudo de caso utilizado em nosso trabaiho do pro jeto »Metodología GIM para la formación a distancia» desenvolvido pelo “Grup de Recerca Escola Multimedia UPC' Trabaihos anteriores como a seleçdo de referéncias bibliográficas e urn estudo sobre modelagem, ayaliaçJo e melhora do processo de software do citado pro jeto, forarn utilizados corno material de apoio. Os principais resultados da nossa pes quisa incluern (1) a taxonornia proposta e (2) as considera çóes metodológicas para os procedirnentos de aplicaçáo dos Testes de Usabilidade ern sistemas interativos multirnídia para a formaçáo a distáncia. Comentamos as conclusóes obtidas através desta pesquisa e as propostas para trabalhos futuros.
\end{abstract}

\section{Testes de Usabilidade - Teste Semántico- Teste Sintático - Teste Exploratório - Teste Comparativo - Teste de Verificação.}

ABSTRACT: in this work we present a study that comes to contribute with concepts and taxonornies for the development of a methodology of structuring, implantation and application of Usability Testing on interactive multimedia systems in distance education. The used case study is the » Metodología GIM para la formación a distancia» pro ject developed by the "Grup de Recerca Escola Multimedia UPC". Previous works such as the selection of bibliographic references and a study about modelling, evaluation and improvement of the software process of this pro ject, were used as support material. The principal discoveries of our research include (1) the proposed taxonomy, and (2) the rnethodological considerations for the proceedings of Usability Testing application in the interactive multimedia systems used in distance education. We comment on the conclusions obtained from analysing the result of this research and we put forward sorne suggestions for future works.

\section{Usability Testing - Semantic Testing - Syntactic Testing - Exploratory Testing - Comparative Testing - Verification Testing.}

\section{ORGANIZAÇÃO DO ARTIGO}

Este artigo está organizado em seis seçóes. Na primeira seçáo procedemos com urna breve introduço corn respeito á nossa pesquisa, onde apresentamos (1) o projeto e a organizaço que foram utilizados como estudo de caso, (2) algumas consideraçóes acerca da importáncia da investigaçao desenvolvida e (3) alguns comentários sobre os estudos e trabaihos prévios. Na seçAo seguinte, aclaramos os aspectos metodológicos da pesquisa. A contextualizaçán dos Testes de Usabilidade é o tema que propomos na terceira seçáo. Na quarta seçá.o apresentamos urna classificaçán para os Testes de Usabilidade e os objetivos (gerais e específicos) dos testes. Na quinta seço comentamos nosso estudo sobre a aplicaçáo dos Testes de Usabilidade considerando (1) as fases do projeto (processos de desenvolvimento de software) e 
(2) a avaliaçáo dos processos relacionados com cada fase do projeto, procedimento que denominamos de metateste. Na sexta seçáo comentamos as conclusóes obtidas e propomos alguns trabaihos futuros. Finalmente, apresentamos as referéncias bibliográficas que foram utilizadas para o desenvolvimento desta pesquisa.

\section{INTRODUCÃO}

O objetivo desta pesquisa é contribuir com um modelo de aplicaçán de Testes de Usabilidade considerando a taxonornia que apresentamos e propomos aqui e aplicá-lo a projetos de desenvolvimento de sistemas interativos multimídia com o objetivo de verificar a eficiéncia do mesmo.

Nosso estudo de caso é o projeto «Metodología GIM1 para la formación a distancia» desenvolvido pelo “Grup de Recerca Escola Multimedia UPC2”, sob a direç o do professor Dr. Josep M Monguet. O projeto é basicamente definido em duas etapas: desenvolvimento e pós-projeto. Identificamos trés fases durante a etapa de desenvolvimento: inicial, intermediária e final, nas quais seus "protagonistas" srio os protótipos Zero, Alfa e Beta. A etapa pós-projeto é representada pelo produto final (ver Figura 1).

1 A sigla GIM procede do organismo Grupo Interuniversitário Multimídia.

2 Grupo de Pesquisa Escola Multimídia Universidade Politécnica de Catalunha.

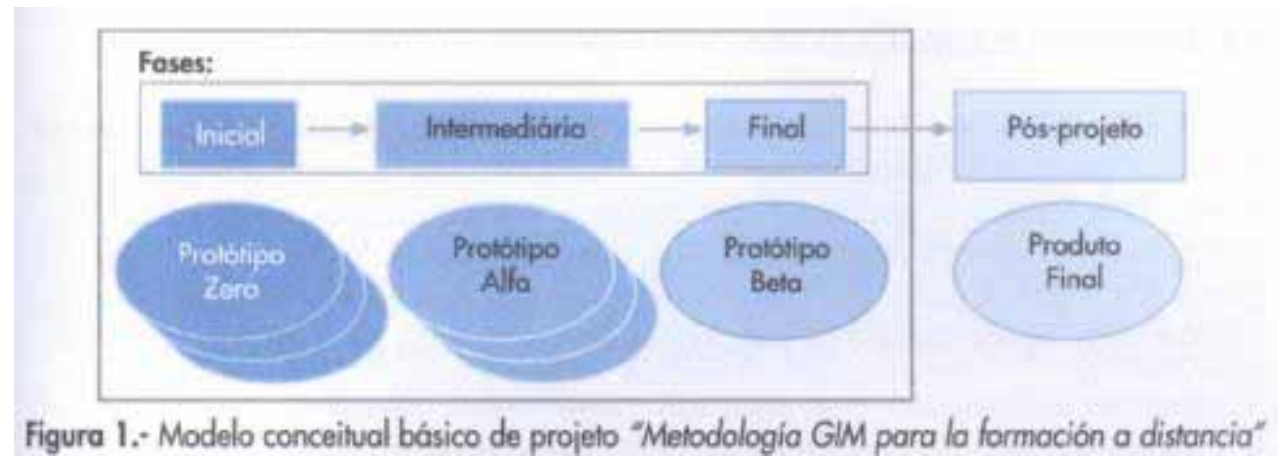

Este projeto tem como finalidade, transmitir técnicas e urna metodologia para os individuos que desejarn desenvolver cursos a distáncia através de sistemas interativos multimídia. Ademais, está em sua fase final de desenvolvimento e, portanto, é onde verificarnos a necessidade dos imprescindíveis Testes de Usabilidade. Por outro lado, observamos que tais testes sAo necessários em quase $60 \%$ dos processos 3 identificados no projeto, dado que nos dá suporte para justificar a importAncia deste trabalho.

Urna considerável quantidade de informaç6es (p.ex. representaçáo gráfica dos processos e datos estatísticos) que apresentamos neste artigo sAo extraídas do (1) trabalho de modelagem, avaliaçáo e meihora do processo de software e (2) de anotaçóes de um estudo preliminar experimental nAo publicado de Pereira (1999) sobre Testes de Usabilidade, baseado no projeto supracitado.

\section{ASPECTOS METODOLÓGICOS DA PESQUISA}

Este estudo está baseado na pesquisa qualitativa, na qual vários grupos de epistemólogos defendem as suas respectivas taxonornias (paradigmas ou categorías). Para este trabaiho utilizamos a classificaçáo que define as trés categorías de investigaçAo — positivista, interpretativa e crítica — sugeridas por Orlikowski e Baroudi (1991) e Chua (1986) e citados por Myers (1997).

Analisando o trabaiho realizado por Myers (1997), observamos que esta pesquisa situa-se corno Interpretativa devido a fatores, como por exemplo, a necessidade de entender o contexto e as influéncias do mesmo (relaçáo cíclica). Ademais, a estratégia de desenho e aquisiçAo de dados que utilizamos foi o método de Estudo de Caso e a Narrativa e Metáfora como modelo de análise, já que trabaihamos com as relaçóes entre os fabricantes de software e a organizaçAo (respectivamente, Grupo GIM e a Escola Multimedia UPC). ${ }^{4}$ 
3 A análise dos processos do projeto «Metodología GIM para la formación a distancia» foi realizada considerando todas as fases do projeto, ou seja, fases: inicial, intermediária e final.

4 Em alguns momentos foi necessário utilizar algumas características de outra taxonomia, método de pesquisa e/ou modelos de análise.

\subsection{ESTRUCTURA I1 LA INVESTIGACIÓN}

A idéia inicial é a de conceitualizar os Testes de Usabilidade e propor urna taxonomia que possa cumprir o papel de catalizadora e aclaradora dos géneros dos testes. Procedendo a aplicaçáo dos mesmos conseguiremos obter mais informaçóes sobre os perfis dos usuários e/ou sugerir modelos de documentos para registro dos testes. A partir dos resultados obtidos, realizamos avaliaçóes e sínteses dos mesmos, apresentando as conclusóes e as propostas para futuros trabaihos.

\section{CONCEITOS DOS TESTES DE USABILIDADE}

Ao termo "teste" (testing) nos referimos ás verificaçóes realizadas nos produtos 5 (processos e protótipos) com o objetivo de identificar os problemas e sugerir mudanças. Outros termos podem e sáo utilizados para representar os testes, como por exemplo verificaçóes, exámes, provas ou revisóes; logo,

Definiçáo 1: O Teste é o procedimento de análise no qual se examina a exatidcio e a qualidade de algo.

Guillemette (1989) argumenta que o termo «usabilidade» (usability) se refere ao grau de efectividade de um documento em re1aç.o aos leitores destino. É uma definiço específica do ámbito da documentaçáo. Considerando as devidas proporçóes, podemos generalizar o termo ao ámbito dos produtos, no qual um documento é um produto, assim como um sistema interativo multimídia ou um processo de software; portanto:

Definiçáo 2:A Usabiidade é o grau de efetividade de um produto em relaçdo ao seu usuário destino.

Considerando a uniao das definiçóes apresentadas anteriormente, propomos a seguinte definiço para os Testes de Usabilidade:

Deflniçáo 3: Os Testes de Usabffidade sco os procedimentos de análise nos quais verificamos o grau de efetividade de um produto em relaçdo ao seu usuário destino.

Os Testes de Usabilidade possuem características diferentes de acordo com as etapas em que se encontram os protótipos, ou seja, que para cada protótipo utilizamos diferentes critérios de avaliaçáo (ver Figura 1 e 4).

No livro Handbook of Usability Testing: How to plan, design and, conduct ef- fective tests, Rubin (1994, p. 25) utiliza o termo Testes de Usabilidade da seguinte maneira:

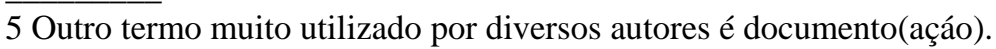

"(...) 1 will use the term usability testing to refer to a process to evaluate the degree to which a product meets specifzc usability criteria. (...)»

A definiço dos critérios de usabilidade está diretamente ligada ao tipo de produto proposto e a tecnologia que possibilita seu uso. Por exemplo, para o pro- jeto «Metodología GIM para la formación a distancia » existem diversos critérios de usabilidade, como a utilizaçto do software em CD-ROM ou a visualizaçáo de um filme como parte do curso, o que implica em requerimentos específicos de hardware (o leitor de CD-ROM e urna placa gráfica de vídeo de alta resoluço); ou amda as consultas realizadas pelos alunos aos tutores, o que implica em requerimentos de telecomunicaço (um sistema eficiente de correio eletrónico).

\section{TAXONOMIA}


Os Testes de Usabilidade gerais podem ser enfocados de acordo com o género de sua taxonomia. Apresentamos nesta seço a taxonornia dos testes (1) quanto às fases do projeto: inicial, intermediária, final e pós-projeto; (2) quanto aos métodos de procedimento: testes exploratórios, comparativos e de verificaç o; e (3) quanto á natureza da verificaçáo: testes semánticos e sintáticos (ver Figura 2).

Observamos que o segundo e terceiro géneros ou classes dos testes so considerados como princípios de apIicaçto nos testes do primeiro género, ou seja, para proceder a avaliaço de cada protótipo produzido durante o processo de desenvolvimento de software devemos utilizar como referéncia os princípios semánticos e sintáticos em cada protótipo, assim como os métodos exploratório, comparativo e/ou de verificaço.

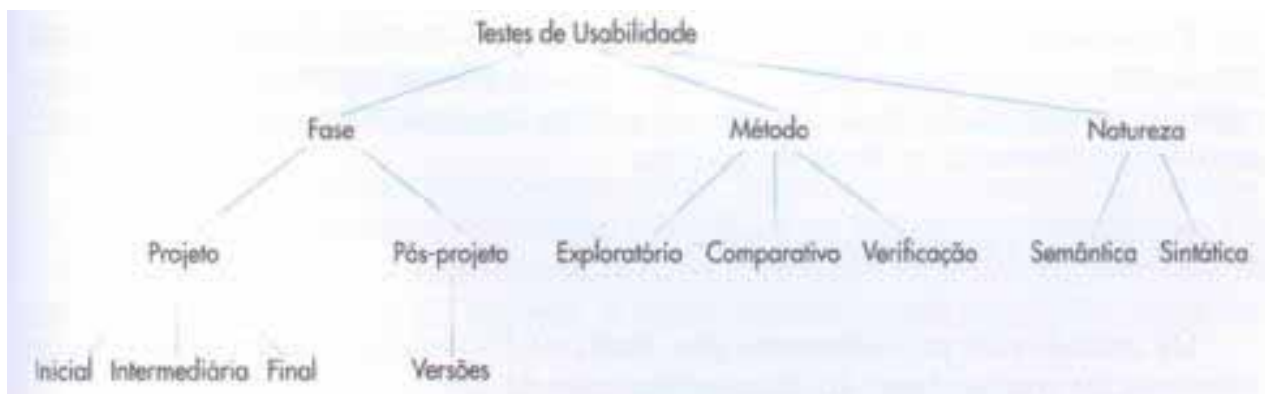

Figura 2.- Taxonomia geral dos Testes de Usabilidade

Vale ressaltar que esta estrutura de aplicaçáo de Testes de Usabilidade pode ser realizada de maneira formal ou informal. Atlas (1981) e Grice e Ridgway (1989) comentam acerca da formalidade dos procedimentos de testes e suas inter-relaçóes.

\subsection{FASES D0 PROJETO}

O trabalho de modelagem, ava1iaço e melhora do processo de software realizado para o projeto «Metodología GIM para la formación a distancia»

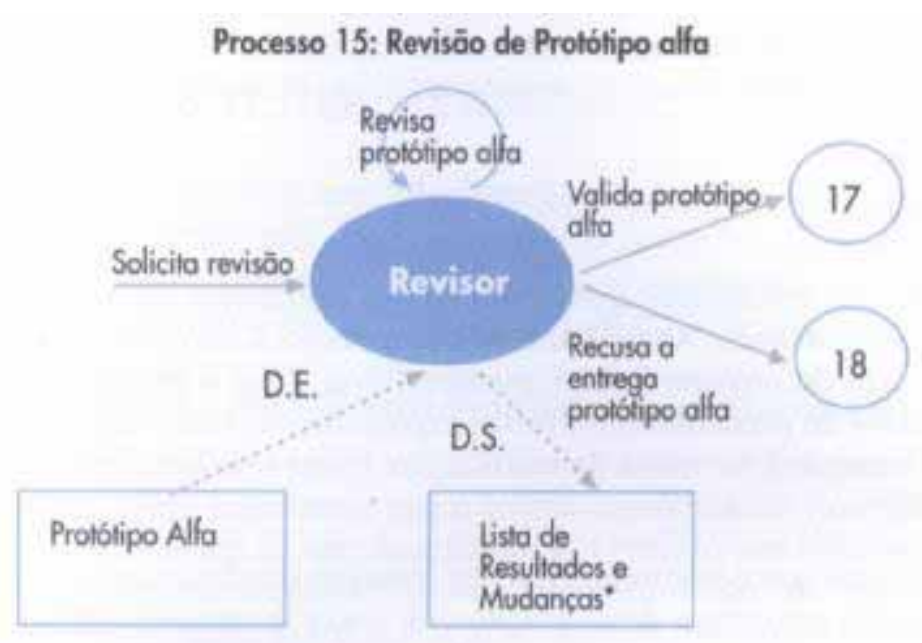

Figura 3.- Revisõo do protótipo alfa. Fragmento de um dos processos identificados a partir do estudo de modelagem, avaliação e melhora do processo de software do projeło "Metodologia IM para la formoción a distancia"

Estes tipos de testes devem ser aplicados em todos os protótipos gerados em um projeto de desenvolvimento de software. Cada software possue características específicas, logo os Testes de Usabilidade podem ser realizados em diferentes momentos considerando as fases do projeto. 


\subsection{METODOS DE PROCEDIMIENTO}

Os métodos de procedimento dos Testes de Usabilidade estáo estreitamente relacionados com as fases do desenvolvimento de um projeto.

Rubin (1994) basando-se em sua taxonomia indica para cada fase do ciclo de vida de desenvolvimento de um produto quais so os tipos (métodos) de testes aplicados. Grice e Ridgway (1989) identificam em que fase de um projeto os métodos de testes sáo utilizados. A seguir apresentamos na Figura 4 um esquema de aplicaço dos métodos de testes de acordo com Rubin (1994) e Grice e Ridgway (1989).

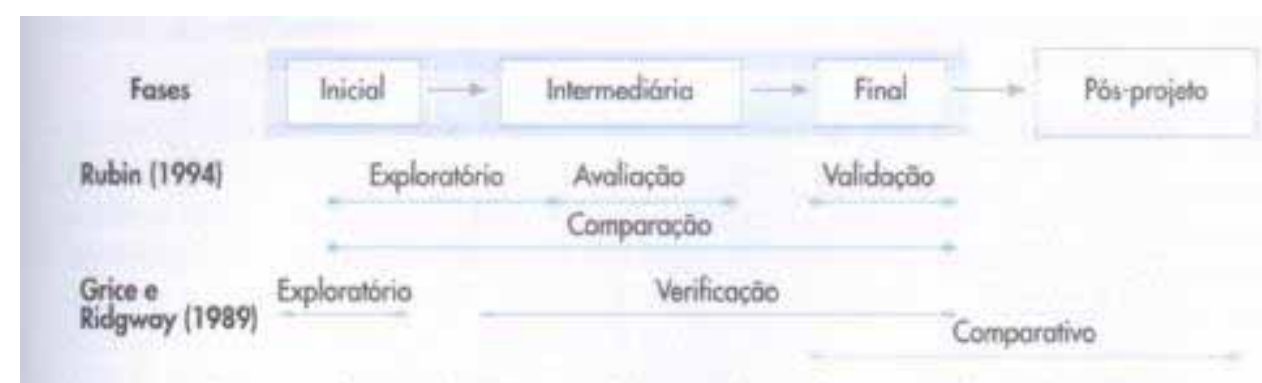

Figura 4.- Aplicação dos métodos de procedimiento de acordo com as fases do projeto

\subsection{NATUREZA DOS TESTES}

A natureza da verificaçáo representa os princípios semánticos e sintáticos que estáo envolvidos no procedimento de aplicaçáo dos testes.

Vale ressaltar que tanto o tipo semántico quanto o sintático so utilizados nos testes realizados em cada fase de desenvolvimento do pmjeto citadas anteriormente, ou seja, o revisor (e em alguns casos específicos, outros membros da equipe) realiza as verificaçóes semánticas e sintáticas para cada protótipo produzido ao longo do ciclo de vida do desenvolvimento do produto final.

\subsubsection{Testes Semánticos}

A palavra semántica de acordo com alguns dicionários (D.R.A.E., 1992; Oxford, 1995 e Aurélio, 1986) significa o estudo do significado dos signos, palavras e linguagens.

Observamos que os procedimentos deste tipo de avaliaçáo estáo relacionados aos aspectos «psicomotores» (atividades mentais e motrizes) do individuo. E importante que os revisores tenham conhecimentos sobre outros campos da ciéncia, como por exemplo, a Ergonomia e a Psicologia, para realizar este tipo de tarefa.

Neste tipo de testes é considerado o fator interaçáo usuário-sistema, ou seja, os elementos que permitem meihorar a interface de usuário: (1) metáforas, (2) mnemónicos, (3) cores e suas teorias, (4) tipo e tamanho de letras, (5) desenho da informaço e (6) análise de tempos. A seguir apresentamos uma visáo mais detalhada destes elementos:

1. Metáforas: So simulaØes do espaço conhecido, ou seja, dos modelos padróes (concretos e familiares) para a resoluçáo de problemas interativos. As implicaçóes diretas desta técnica sAo a velocidade e o uso da intuiçáo na compreensáo da informaçáo. Ademais, Díaz, Catenazzi e Aedo (1996, p. 100) sintetizam que para conceber as metáforas se de- ve “(...) utilizar conceptos y modelos del mundo real con los cuales los usuarios están familiarizados, para representar información electrónica (...)“. Exemplos de metáforas: biblioteca, livro, mesa de escritório, museu, etc.

2. Mnemônicos: A arte de recordar associando o objeto em questáo (p.ex. comandos ou imagens) a contextos conhecidos (p.ex. relaçóes numéricas, abreviaçóes ou ícones). O revisor deve aproveitar esta técnica para analisar as ferrarnentas cognitivas utilizadas em sistemas interativos multimídia para a formaçáo a distáncia. Este tipo de estudo permite relaçóes entre o conteúdo 
topológico e a reproduçáo da localizaçáo de memóna visual quando trabaihamos com o conceito hipermídia, como argumenta Wrede (1997). Ademais, Wrede (1997, p. 129) argumenta que «The elements of known interfaces are standardized, but they increasingly potentially allow individual specifications to be taken into account and create unique ordering systems (or disorder) which provide externa! reference points for the internal medium of remembering. (...)», o que demonstra que existe uma forte relaçáo entre os elementos metáfora e mnemónicos, Exemplos de usos específicos de esta técnica: os símbolos que posuem alguns sistemas operacionais de interface “crua” (p.ex. UNIX ou DOS), onde está representada a disponibilidade de executar comandos. Essa característica necessha mais estudo mnemónico, já que ern sistemas operacionais de interface "gráfica”, existe urna rápida associaçáo de conhecimento entre urna imagem e sua «funçáo».

3. Cores e suas teorías: O revisor deve possuir conhecimentos básicos das cores para identificar os elementos que náo estáo de acordo com a informaçáo que se deseja transmitir. Ademais, ele deve manter em mente algumas consideraçóes relacionadas ás cores e seus significados, para realizar sua tarefa de verificaçáo, como por exemplo as interpretaçóes do simbolismo cromático que sáo apresentadas na Tabela 1:

Tabela 1: Interpretaç̄es do simbolismo cromático segundo Juan Eduardo Cirlot.

\begin{tabular}{|l|l|}
\hline Cor & Interpretozöes simböicas \\
\hline Azul & Atributos de religioso e a inocẻncia \\
\hline Verde & A natureza e a simpatia \\
\hline Violeta & Nostalgia ou lembranças \\
\hline Amarelo & Intuiçäo, generosidade e intelecto \\
\hline Alaranjodo & Orgultho \\
\hline Vermelho & Paixào \\
\hline Cinza & Neutralidade e indiferença \\
\hline Púrpura & Poder e espiritualidade \\
\hline Rosa & Carne e sensualidade \\
\hline
\end{tabular}

Identificamos o uso destas interpretaçóes simbólicas nos aspectos culturais, profissionais, pessoais e outros. O branco pode ser interpretado segundo o poyo que o utilize, por exemplo, paz para muitos dos países ocidentais. Para os povoadores da Antártica, no existe um branco, sen.o muitas tonalidades ao redor do branco, onde cada urna delas significa algo diferente. Em geral, a psicologia experimental e a ótica, classificarn as cores em dois grandes grupos: (1) cores ativas (-avançam no espaço) e (2) cores passivas (retrocedem no espaço). Na Tabela 2 apresentamos a relaç o nos níveis psíquico e representativo:

Tabela 2: Relação nos niveis psiquico e representativo.

\begin{tabular}{|l|l|}
\hline Cor & Relocão \\
\hline Amarelo & É intuição \\
\hline Alaranjado & É o fogo ou as chamas \\
\hline Azul & Reflete pensamento \\
\hline Marrom & É a terra \\
\hline Vermetho & Representa os sentidos e o sangue \\
\hline Verde & Éoperceptivo \\
\hline
\end{tabular}

Shneiderrnan (1998) argurnenta que o uso das cores é urna técnica importante para conseguir a atenç<0 do usuário.

Neste artigo náo pretendemos apresentar um estudo aprofundado sobre as cores, porérn acreditamos na importáncia desta introduço para que o revisor desempenhe com eficácia seu papel. 
- Tipos e tamanho das fontes: Este elemento está representado pelas características da tipologia, ou seja, constituiçáo de um projeto gráfico considerando as relaçóes entre a tipologia do texto e o que ele representa ou quer enunciar. Para conseguir a atençáo do usuário, Shneiderrnan (1998) sugere, entre outras técnicas, que utilizemos para as fontes urna variaçáo de quatro tamanhos e trés tipos. Estas recomendaçóes sáo importantes observaçóes que o revisor deve ter em mente para realizar urn Teste de Usabilidade eficaz.

- Desenho da informaçáo: Segundo Mok (1998, p. 108), «Es la disposición de modelos de organización para proporcionar contexto y significado a la información» e está baseado na compreensáo da inforrnaçáo e das relaçóes entre as suas partes, ou seja, é a concepçáo de uma linguagem comum. Este elemento é o resultado dos elementos anteriores. Para que um revisor realize sua tarefa considerando este elemento, ele deve ao menos conhecer, além dos elementos apresentados, as características da informaço, como por exemplo a quantidade, a consisténcia, a arquitetura (p.ex. página web e/ou revista), a estrutura (p.ex. linear, hierárquica e/ou hiperestrutura) e os tipos mídia apropriados. A topologia da informaç o é muito importante para o entendimento da mesma (Guillernette, 1989).

- Análise de tempos: Este elemento deve ser considerado principalmente nas etapas finais do projeto (quando o protótipo beta já esteja em execuç o e sendo testado pelos usuários de teste) e no uso final do produto por parte do usuáno final. A tomada de tempos ern urna prirneira fase produzirá um marco para as estimativas do uso do produto. No caso de sistemas interativos multimídia para a formaçáo a distáncia os tempos estáo relacionados diretamente com o uso do material educativo e so tornados com o objetivo de proporcionar urna avaliaçáo que se aproxime ao máxirno da realidade, já que o tempo de leitura no representa urna real retençáo de conteúdo por parte do usuário e o tempo de cornpreensáo sim. A seguir, na Tabela 3 apresentamos urna proposta para a previso do tempo medio de leitura considerando os fatores técnico e de usabilidade.

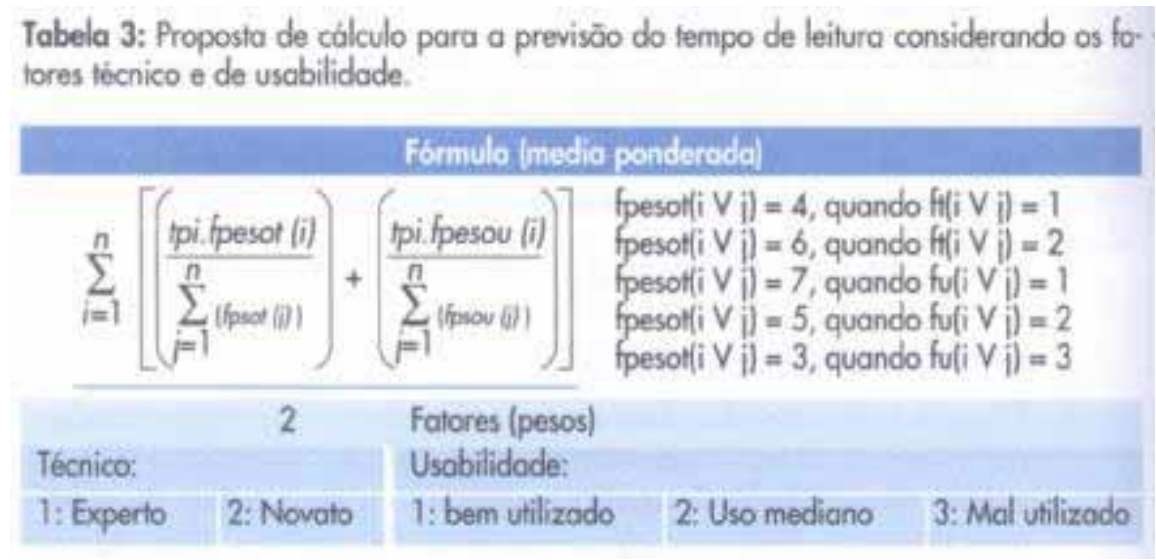

As funçóes fpesot() e fpesou() representam os pesos utilizados no cálculo do tempo de leitúra, e esto diretarnente relacionadas com as características (1) ft: Fator Técnico e (2) fu: Fator Usabilidade do estudante (ver fórmula na Tabela 3). A idéia é atribuir diferentes pesos6 aos ternpos de leitura (de cada módulo) do estudante.

Os Fatores Técnicos influenciam na estimativa do tempo porque a experiéncia dos usuários de teste está vinculada com os conceitos utilizados cm informática, ou seja, se um usuário é considerado urn experto, ele identifica rapidamente os símbolos e estruturas que sáo comuns ern sistemas informáticos, reduzindo assim os procedimentos de busca de funçóes e de uso de alguns periféricos multimídia. Porém se o usuário é um novato, muitos procedimentos s.o novos, logo sua curiosidade e fascinaç to o deixa inicialmente perdido, e isso aumenta seus tempos (leitura ou compreensto). Recomendamos a realizaçáo de um treinamento prévio dos usuários pelo revisor.

Os Fatores de Usabilidade no podem ser identificados no documento Perfil del usuário, devido ao fato de que tal inforrnaço é obtida através de urna observaçáo cm tempo real.

A tomada dos tempos de compreensáo é muito difícil de se obter. Vários aspectos relacionados ás características pessoais de cada usuário influem decisivamente nas estimativas e previsóes iniciais do projeto. Como ponto de partida, recomendamos a utilizaço do grupo de usuários de teste. 
Estes elementos ainda sao temas de pesquisa que estáo sendo desenvolvidos por urna grande quantidade de profissionais e académicos. Porém, o enfoque proposto neste trabalho está sob o ponto de vista do revisor, e questóes técnicas de cada elemento devem ser resolvidas por seus respectivos especialistas, correspondendo ao revisor a tarefa de identificaçao de falhas na apresentaçao destes elementos e produçao de relatórios de resultados e sugestóes para possíveis mudanças.

\subsubsection{Testes Sintáicos}

Utilizamos a mesma consideraçáo metodológica para começar a abordagem dos Testes Sintáticos. A palavra sintaxe, de acordo com diversos dicionários (D.R.A.E., 1992; Oxford, 1995 e Aurélio, 1986), significa o estudo da coordenaçao e construçao gramatical para formar as oraçóes e expressar conceitos.

Definirnos como Testes Sintáticos os procedimentos de avaliaçao de um produto onde enfocamos os problemas de natureza técnica (comandos, objetos, regras e suas relaçóes mútuas) e de conteúdo da informaçáo (j.c. conteúdo por conteúdo). Guillemette (1989) utiliza o termo funcionalidade quando se refere ás características de natureza técnica.

As considerançóes que devem ser observadas quando produzimos urn Teste Sintático sao resultantes de urna análise apoiada nos fatores: (1) erros de programaçao, (2) características do sistema autor, (3) portabilidade de equipamento, (4) erros gramaticais e outros do género. A seguir apresentamos urna visao mais detalhada destes fatores.

Erros de programaçáo: Este fator proporciona urna verificaçáo nos códigos, objetos e regras da linguagem de programaçáo utilizada7. Existen muitos tipos de problemas que podemos identificar na programaçáo, porém eles sáo dependentes de cada caso analisado, como por exemplo mau funcionamento do mouse, associaçóes equivocadas entre comandos ou objetos e suas funçóes, escoiha de algoritmos deficientes para urna determinada funçáo e resultados inesperados.

Características do sistema de autoría: Para este fator devemos ter em mente as vantagens e desvantagens (p.ex. linguagem gráfica e limitaçóes técnicas do sistema de autoria8, respectivamente) que possue a linguagem. Este deveria ser urn procedimento pré-compra, porém na maioria dos casos verificamos suas características quando um determinado pro- jeto já se encontra em execuçáo, ou seja, a linguagem já foi comprada e a equipe de programadores já está sendo treinada como mínimo.

Portabilidade de equipamento: Este tipo de fator determina muitas características do projeto, como (1) o perfil dos usuários interessados9 que, por sua vez (2) implica diretamente nos custos do projeto, já que pode ser necessário desenvolver o software para diferentes plataformas, como PC ou Macintosh. O avance tecnológico que caminha em paralelo ao projeto, e náo só a este, influencia a definiçáo dos requisitos de hardware (p.ex. quantidade de memória RAM; tipo de teclado, mouse e/ou joystick; velocidade de um leitor de CD; placa de vídeo; etc.) necessários para que o produto final tenha éxito.

Erros gramaticais (e outros do genero): Este fator consiste em verificar se o conteúdo proposto está de acordo com as regras de seu idioma, ou seja, se os dados (palavras, símbolos, sinais, etc.) estáo cumprindo sua funçáo sintática e produzindo a semántica real da informaçáo que desejamos passar ou dispor. Este fator possue forte relaçáo com urna parte dos Testes Semánticos.

Os Testes Sintáticos possuem um carácter mais específico, ou seja, as consideraçóes observadas pelo revisor posuem níveis mais baixos se comparadas ás dos Testes Semánticos que posuem circunstáncias próprias mais genéricas e, por- tanto, representa os níveis mais altos dos testes gerais de usabilidade. Em resumo, o grau de abstraçáo de um Teste de Usabilidade aumenta quando nos aproximamos da parte semántica e diminue quando nos aproximamos da parte sintática (ver Figura 5). 


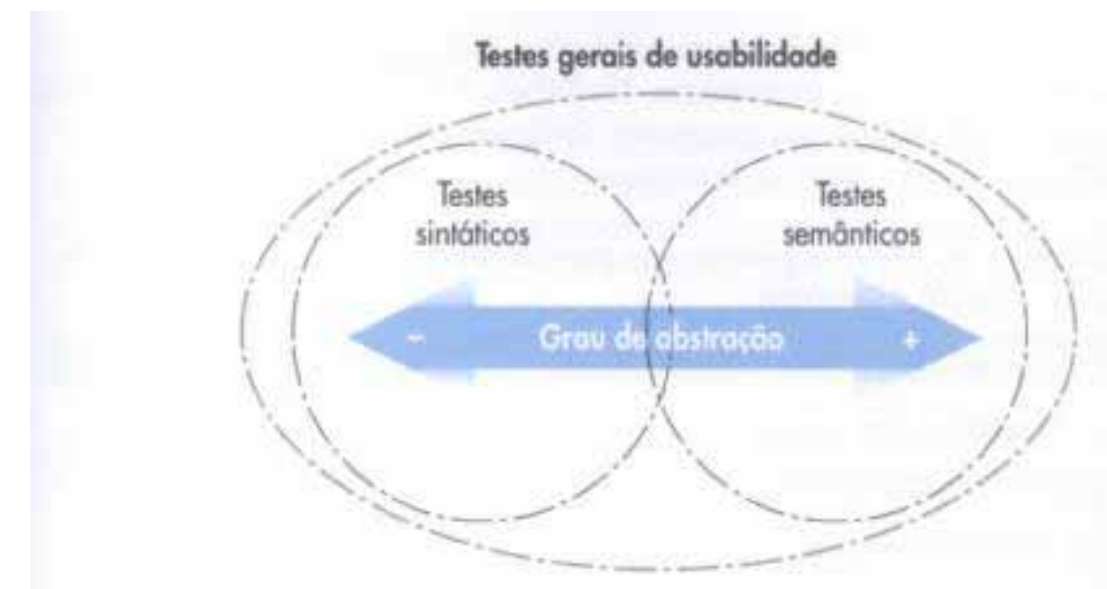

Figura 5.- Grau de abstraçāo dos testes gerais de usabilidade

A forte relaçáo que existe entre algumas características dos Testes Semánticos (desenho da informaço) e Sintáticos (erros gramaticais) é representada pela área de interseçáo na Figura 5.

\subsection{OBJETIVOS DOS TESTES}

As tarefas de verificaçAo e correçáo de problemas para meihorar e otimizar um determinado producto é o objetivo principal dos Testes de Usabilidade. Segundo Rubin (1994, p. 26), «The overa!! goal of usability testing is to identify and rectify usability deficiencies existing in computer-based and eletronic equipment and their accompanying support materials prior to release. (...)». Os objetivos dos Testes de Usabilidade podem ser classificados como (1) gerais e (2) específicos.

\subsubsection{Objetivos Gerais}

Estamos de acordo com Rubin (1994) quando ele comenta que os principais objetivos gerais dos Testes de Usabilidade se caracterizam por garantir (1) facilidade de aprendizagem e de uso, (2) satisfaço do uso, (3) publicidade quando se garante utilidade e funcionalidade do produto, (4) registro histórico de temas de usabilidade para futuros testes, (5) reduçáo de custos de serviços e (6) reduçAo de riscos.

\subsubsection{Objetivos Específicos}

Os objetivos específicos dos Testes de Usabilidade sAo mais peculiares, devido ao fato de que cada verificaçAo ou grupo de verificaç6es sAo dependentes de protótipos (subprodutos) que sAo desenvolvidos durante o processo de software.

Podem existir muitos objetivos específicos na aplicaçáo dos Testes de Usabilidade en sistemas interativos multimídia. Na Tabela 4 apresentamos os objetivos específicos que identificamos nos processos de desenvolvimento do projeto «Metodología GIM para la formación a distancia». 


\begin{tabular}{|c|c|}
\hline Objetivos especificos & Participantes \\
\hline Comprovar e revisar o protótipo zero & Chefe de produçōo, Autor, Editor \\
\hline Verificar os gráficos do protótipo alfa & Chefe de grafistas \\
\hline $\begin{array}{l}\text { Verificar o funcionamento geral do } \\
\text { prolótipo alfa }\end{array}$ & Chefe de produçāo, Aulor, Editor, Revisor \\
\hline $\begin{array}{l}\text { Verificar o funcionamento geral do protótipo } \\
\text { beto }\end{array}$ & Chefe de produçāo, Revisor \\
\hline $\begin{array}{l}\text { Avaliar os usuários de teste que utilizom o } \\
\text { protótipo beta. }\end{array}$ & Revisor \\
\hline $\begin{array}{l}\text { Verificar of funcionomento geral do } \\
\text { produto final }\end{array}$ & Revisor \\
\hline $\begin{array}{l}\text { Avaliar o produto final em relaçāo a outros } \\
\text { produtos }\end{array}$ & Chefe do projeto, Revisor \\
\hline
\end{tabular}

\section{APLICAÇÁO DOS TESTES DE USABILIDADE}

Os Testes de Usabilidade podem ser aplicados durante as diversas fases de um projeto (ver Figura 4). Grice e Ridgway (1989) argumentam que no ciclo de desenvolvimento de um documento se pode avahar as concordancias entre elementos e seus propósitos, por exemplo: (1) antes do início o revisor pode avahar apropriadas metáforas, definiçóes e objetivos; (2) depois do desenho inicial, o revisor pode avahar se o conceito pretendido se encaixa com os usuários; e logo (3) no desenho completo o revisor pode avahar o grau de efectividade em que tal documento se encontra e verificar sua aceitabilidade.

No projeto «Metodología GIM para la formación a distancia» foram produzidos os protótipos zero, alfa e beta (ver Figura 1). Para iniciar a aphicaç o dos Testes de Usabilidade, consideramos cada protótipo desenvolvido no projeto separadamente. Aplicamos a cada protótipo os Testes de Usabilidade utilizando as características específicas regidas pelos objetivos de cada fase do projeto. Logo, apresentamos uma sugestao de critérios de aç<o para a reahizaçAo de Testes de Usabilidade na etapa final do projeto e nos projetos futuros.

\subsection{FASES DO PROJETO}

Na primeira etapa do trabaiho de modelagem, avaliaçáo e meihora do processo de software realizado para o projeto supracitado, identificamos um total de vinte e quantro processos para o desenvolvimento de software. Dos quais quatorze processos (aproximadamente $58 \%$ do total de processos) possuem características de verificaçáo, comprovaçáo, revisáo e avaliaçáo, ou seja, sáo processos de testes. A partir das conc1uses obtidas desse trabaiho de apoio e dos trabaihos desenvolvidos por Gould e Lewis (1985), Grice e Ridgway (1989), Guillernette (1989), Sullivan (1989), Rosenbaurn (1989), Wenger e Spyridakis (1989) e Rowley (1994), dentre outros autores que tratam sobre questóes teóricas dos Testes de Usabilidade; das pesquisas sobre a usabilidade de manuais de usuários apresentadas por Atlas (1981) e Maynard (1982); das propostas apresentadas por Garzotto, Mainetti e Paolini (1995) do modelo HDM (Hypermedia Design Model); e de muitos outros trabaihos apresentados por vários autores, como por exemplo, Buur e Bagger (1999), Gardner (1999), Dolan e Dumas (1999) e Hammontree, Weiler e Nayak (1994), consideramos os Testes de Usabilidade, sob os pontos de vista «ava1iaço orientada ao usuário" e "ava1iaço orientada ao desenho", como procedimentos de fundamental importáncia nos projetos de desenvolvimento de software.

Os Testes de Usabilidade devem possuir urna característica recursiva e sua aplicaçáo deve estar presente em todos os processos do projeto de desenvolvimento de software, como podemos observar na Figura 6 e Figura 7.

Podemos proceder a aplicaço dos Testes de Usabilidade considerando o fluxo de informaço processual que apresentarnos na Figura 6. Este procedimento é caro devido ao fato de que se existe um erro, o fluxo 
de informaço e de execuçáo de processo retorna ao inicio do ciclo e alguns processos podem ser novamente revisados sem necessidade, aumentando assim o custo do projeto.

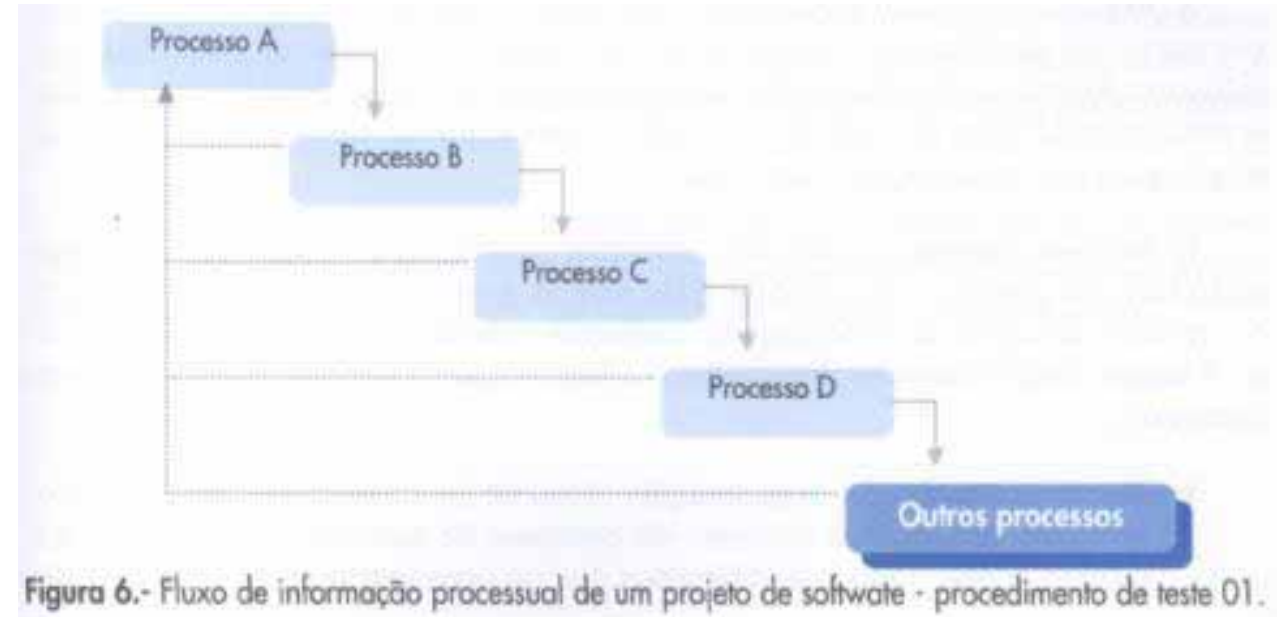

Por outro lado, o procedimento de teste representado na Figura 7 é rentemente mais caro, considerando que existem subciclos, o que aumenta o fi xo de informaço e execuçáo de processo. Porém se ocorre um erro, podemo rregí-lo imediatamente onde foi identificado sem a necessidade de retornar ac início do projeto e isso baratea o custo final do projeto. Autores como Atlas (1981) e Gould e Lewis (1985) argumentam em favor das repetiçóes de processos para as tarefas de ediçáo e reviso, pois elas conduzem a um refinamento dos procedimentos de teste.

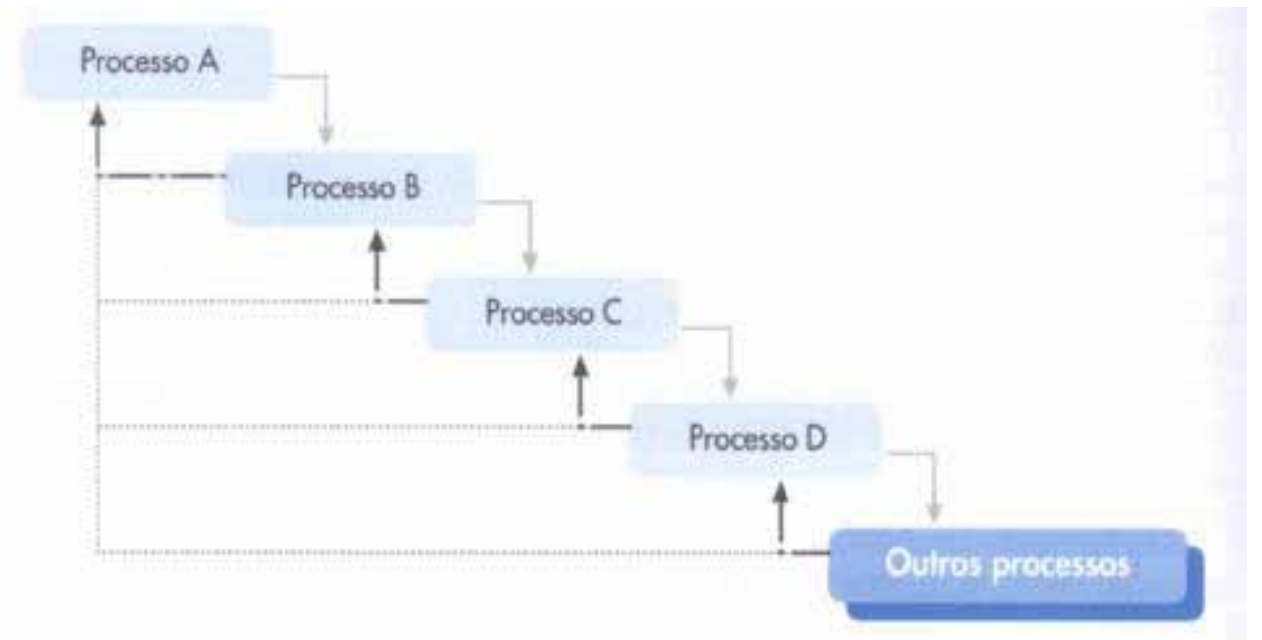

Figura 7.- Fluxo de informoção processual de um projeto de soltwate - procedimento de teste 02.

\subsection{AVALIACÁO DOS PROCESSOS: UM METATESTE}

A proposta de avahar processos é um tema de pesquisa e de muito trabalho por parte dos académicos e profissionais que esto envolvidos em engenharia de software. Aspectos específicos das metodologias de processo de software (software process) e de fluxo de trabaiho (workflow) esto sendo estudados e geram urna arnpla gama de pubhicaçóes científicas.

É de nosso interesse apresentar algumas consideraçóes sobre os rnetatestes realizados ao projeto «Metodología GIM para la formación a distancia», a partir do trabalho de apoio de modelagem, avaliaçáo e melhora do processo de software. A seguir, identificamos e detalhamos os tópicos que devern ser tratados em um metateste.

1. Reestruturaçto da organizaçio: A partir do trabaiho de apoio de modelagem, avaliaçáo e rnelhora do processo de software realizado para o projeto supracitado, identificamos que no 
organograrna da equipe de desenvolvimento todas as funçóes com respeito aos Testes de Usabilidade se concentravam apenas ern urna pessoa, denominada Revisor. Depois da análise de reestruturaçáo da organizaço propomos novas funçóes para o Revisor. Esta tarefa permite que os Testes de Usabilidade sejam realizados com mais rapidez, o que reduz o custo do projeto. Por outro lado, novas pessoas devem ser contratadas para as funçóes específicas (p.ex. um revisor para os testes semánticos, um para os testes sintáticos e um chefe de revisores).

2. Reestruturaço das fases do projeto: Se caracteriza pela realizaç.o de (re)engenharia de software, ou seja, a reestruturaçáo do processo de desenvolvirnento de software corn o objetivo de melhorá-lo (Curtis, Kellner e Over, 1992; Botella, 1998; Hesse, 1999).

3. Utilizaço de ferramentas automatizadas e integradas: Apresentamos este tópico corno urna proposta para a adrninistraço do projeto. É aconselhável que procedimentos de modelagem e avaliaçáo de (re)engenharia de software sejam realizados corn o objetivo de rnelhorar o desenvolvirnento do projeto. Para tanto, podemos utilizar linguagens de prograrnaç o de processos de software como as propostas apresentadas por Sutton, Heirnbigner e Osterweil (1995), Finkelstein, Krarner e Nuseibeh (1994), e outros.

\subsection{USUARIOS DE TESTE E USUARIOS FINAIS}

A escoiha das pessoas que corneçar.o os testes depende de alguns aspectos, como por exemplo, o apoio financeiro para contratar usuários de teste e a disponibilidade dos mesmos. Adernais destes aspectos, devemos levar em consideraço as características dos usuários finais que irgo utilizar o produto final (p.ex. para um produto final que consiste em um curso rnultirnídia a distáncia, devernos considerar as características dos alunos, tutores e professores que so os usuários finais deste curso). Portanto, urna boa seleçáo de usuários de teste pode implicar em éxitos prévios.

Na Figura 8 apresentamos um esquema geral dos participantes do projeto «Metodología GIM para la formación a distancia» e podernos identificar, a grosso modo, os diferentes papéis entre os usuários de teste e os usuários finais.

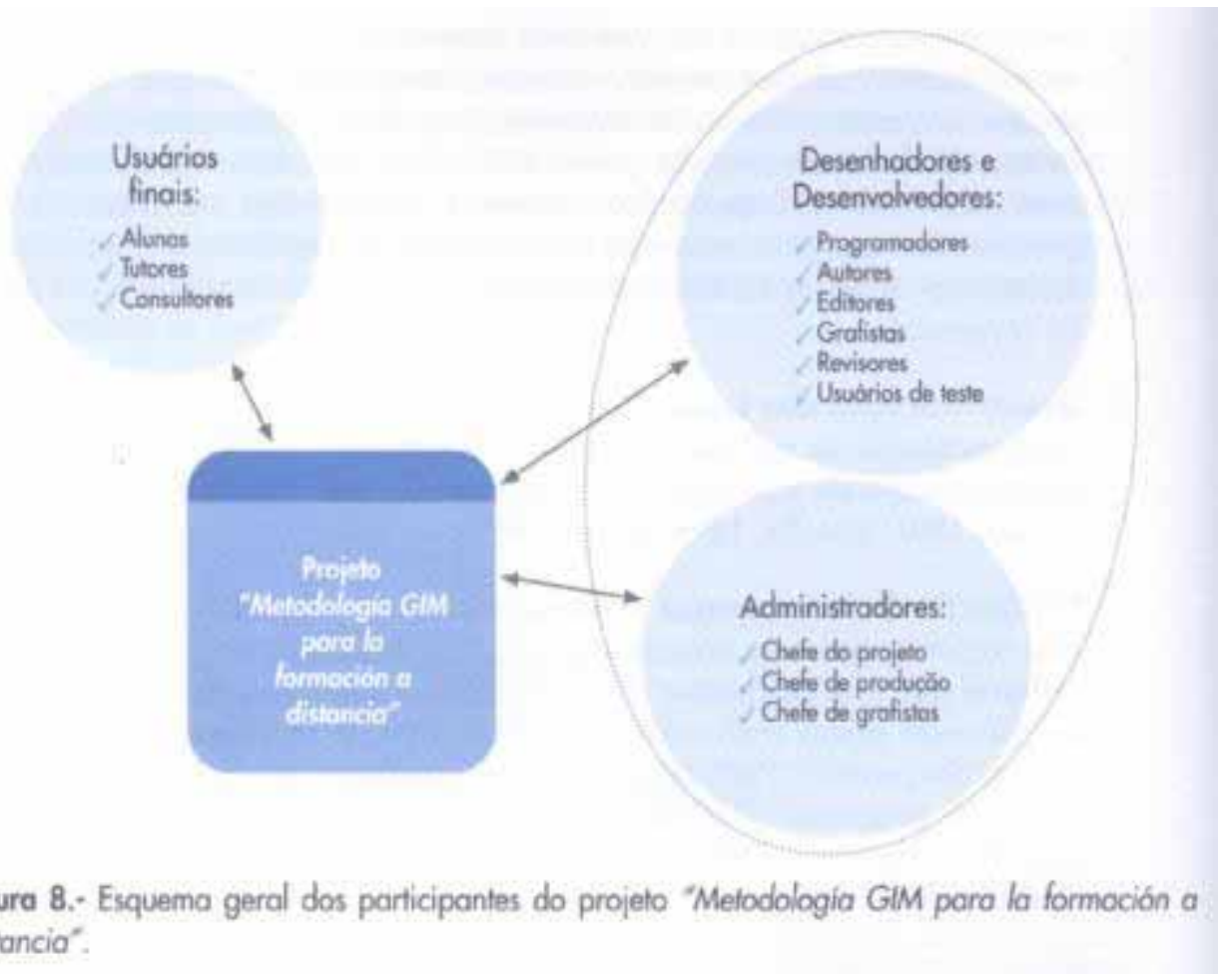

Analisando a Figura 8, observamos que existem dois tipos de usuários do sistema. O primeiro tipo é representado pelos usuários finais e o segundo pelos usuários de teste. É importante levar em consideraçáo os papeis que possuem cada participante do projeto, porque desta maneira podemos 
identificar com precisáo onde começa e acaba as intervençóes de cada um deles. A seguir apresen- tamos as características principais dos usuários.

1. Usuários Finais: So as pessoas que váo utilizar o sistema como ferramenta de trabaiho ou estudo, ou seja, organizaçóes ou individuos que investem em sistemas interativos multimídia para lograr mais eficácia frente concorréncia. Considerando o projeto «Metodología GIM para la formación a distancia», os usuários finais so as pessoas que realizaro o curso, ou seja, os individuos (estudantes) que esto predispostos a investir (e compartir) parte de suas horas diárias (atividades de labor e pessoais) nos estudos.

2. Usuários de Teste: Sáo os participantes com papéis específicos no processo de desenvolvimento de software. Estes indivíduos sáo fortes candidatos a usuários finais (dependéncia do perfil deste tipo de usuário). Considerando projeto «Metodología GIM para la formación a distancia», os usuários de teste sáo as pessoas que esto direta ou indiretamente envolvidas no processo de desenvolvimento do projeto, como por exemplo: programadores, autores, editores, grafistas, revisores, chefe do projeto, chefe de produço, chefe de grafistas e os usuários de teste escolhidos de acordo com critérios predeterminados.

\section{CONCLUSÓES E TRABALHOS FUTUROS}

\subsection{CONCLUSÕES}

Hoje ern dia, é fácil identificar a preocupaçáo depositada na usabilidade de sistemas de computadores, por parte dos membros de um projeto em geral. Os sistemas interativos multimídia para a formaçáo a distáncia náo so um caso a parte, senáo um dos grupos críticos de sistemas de computadores e, portanto, propomos que tais sistemas sejarn projetados levando em consideraçáo os Testes de Usabilidade, consequentemente muitos problemas, como por exemplo, a dificuldade de apredizagem, podero ser resolvidos.

Os Testes de Usabilidade revelam urna procura de informaçóes que podem ser extraídas dos resultados de uso pelos usuários de teste ou finais (clientes). Realizamos esta procura de maneira mais precisa, se ternos um born conhecimento do projeto de software (o que podemos chamar de "caixa negra"). As informaçóes obtidas seráo indicadores do que está bern e do que náo está. Esse feedback é a contribuiç.o principal dos Testes de Usabilidade. Ademias, os Testes de Usabilidade sáo fundamentais para as atividades de produço de sistemas interativos multimídia, devido (1) ao planejarnento, desenvolvimento, operaç.o, controle e manutençáo do projeto; e (2) á otimizaço da transferéncia de información (Pereira e Zúñiga, 1999).

Portanto, acreditamos que a taxonomia apresentada neste artigo contribue como consideraçóes rnetodológicas para a ap1icaço dos Testes de Usabilidade em um projeto de sistemas interativos multimídia para a formaç.o a distáncia e em sua fase pós-projeto.

Rubin (1994, p. 304) argumenta que “(...) When activities such as establishing usability objectives, formally characterizing the user, conducting a task analysis, and establishing testing checkpoints simply become the way to cunduct business,you will know that usability has arrived, and it will be difficult to sabotage. (...)".

\subsection{TRABALHOS FUTUROS}

Pretendemos, a partir de este trabalho, realizar pesquisas acerca das informaçóes resultantes (feedback) do uso de sistemas interativos multimídia, como por exemplo a eficiéncia relativa na frequéncia de uso dos modelos de apresentaçáo e exercitaçáo de conteúdos dos materiais de auto-apredizagem para a formaçáo a distáncia. Por outro lado, estamos realizando urna comparaçáo entre as diferentes condutas de avaliaçAo: orientadas ao usuáno e orientadas ao desenho.

Ademais, resultados de temas de investigaço como mediço do interesse, tempo de aprendizagem, quantidade de solicitaçáo de ajuda e outros sao informaçóes que devem ser fornecidas, devido aos objetivos de conduta que s.o testados (Gould e Lewis, 1985). 


\section{REFERÊNCIAS BIBLIOGRÁFICAS}

ATLAS, M. A. (1981). The user Edit: Making Manuals Easier to User. IEEE Transactions on Professional Communications, PC-24, 28-29.

AURÉLIO. (1986), Novo Diciondrio da Língua Portuguesa. Rio de Janeiro: Editora Nova Fronteira SA.

BOTELLA, P. (1998). Tecnología del proceso software. Con ference Material, Habana: International School on Advanced Programming.

BUUR, J., BAGGER, K. (1999). Replacing Usability Testing with User Dialogue. Communications of the ACM, 42 (5), 63-66.

CHUA, W.F. (1986). Radical Developments in Accounting Thought. The Accounting Review, 61, 60 1632.

CURTIS, B., KELLNER, M., OVER, J. (1992). Process Modeling. CACM, 35 (9), 75-90.

DIAZ, P., CATENAZZI, N., AEDO, 1. (1996). De la Multimedia a la Hipermedia. Madrid: RA-MA Editonal.

DOLAN, W. R., DUMAS, J. S. (1999). A Flexible Approach to Third-Party Usability. Communications of the ACM, 42 (5), 83-85.

D.R.A.E. (1992) Diccionario de la Real Academia de la Lengua Española. Madrid: Editorial Es- pasa Calpe S,A.

FINKELSTEIN, A., KRAMER, J., NUSEIBEH, B. (eds) (1994). Software Process Modelling and Technology. John Wiley and Sons Research Study Press ltd: New York.

GARDNER, J. (1999). Strengthening the Focus on Users' Working Practices. Communications of the ACM, 42 (5), 79-82.

GARZOTTO, F., MAINETTI, E., PA0LIM, P. (1995). Hypermedia Desin, Analysis, and Evaluation Issues. Communications of the ACM. 38 (8), 74-86.

GOULD, J. D., Lnwis, C. (1985). Designing for Usability: Key Principles and What Designers Think. Communications of the ACM, 28(3), 300-311.

GRICE, R. A., RIDGWAY, L. 5. (1989). A Discussion of Modes and Motives for Usability Evaluation. IEEE Transactions on Professional Communications, 230-237.

GUILLEMETTE, R. A. (1989). Usability in Computer Documentation Design: Conceptual and Methodological Considerations. IEEE Transactions on Professional Communications, 217-229.

HAMMONTREE, M., WEILER, P., NAYAK, N. (1994). Remote Usability Testing. Interactions, 1 (3), 2 $1-25$.

HESSE, W. (1999). The Software Process, its Management and Quality Assurance. Course Material, Germany: University of Marburg.

MAYNARD, J. (1982). A User-Driven Approach to Better User Manuals. IEEE Transactions on Professional Communications, PC-25 (1), 16-19.

MOK, C. (1998).. El diseño en el mundo de la empresa. Madrid: Ediciones Anaya Multimedia. 
MYERS, M. D. (1997). Qualitative Research in Information Systems. MIS Quarterly (21:2), June 1997, pp. 241-242. MISQ Discovery, archival version, June 1997, http://www.misg.org/misgd961/iswor1d/. MISO Discovery, updated version, February 24, 1999, http://www.auckland.ac.nz/msis/isworldl.

ORLIKOWSKI, W.J., BAROUDI, J.J. (1991). Studying Information Technology in Organizations: Research Approaches and Assumptions. Information Systems Research, 2, 1-28.

OXFORD. (1995). The Concise Oxford Dictionary os Current English. New York: Oxford University Press Inc.

PEREIRA, H., ZOÑIGA, G. (1999). Tecnologf a de la Información y de la Comunicación en la Educación Continua a Distancia. 1 Jornades Multimedia Educatiu. Barcelona: Universitat de Barcelona.

PEREIRA, H. (1999). Pruebas de Usabilidad: Consideraciones metodológicas. Trabajo desarrollado para la aplicación de pruebas de usabilidad en sistemas multimedia.

ROSENBAUM, 5. (1989). Usability Evaluations Versus Usability Testing : When and Why? IEEE Transactions on Professional Communications, 32 (4), 210-216.

ROWLEY, D. E. (1994). Usability Testing in the Field: Bnnging the Laboratory to the User. CHI-Human Factors in Computing Systems, 252-257.

RUBIN, J.(1994). Handbook of Usability Testing: How to plan, design, andconduct effective tests. New York: John Wiley \& Sons.

SANTOS, N. (1995). Desenvolvimento de Aplicaçóes Hipermídia. Workshop — Multimídia: Da Te- oria ¿1 Prática. Salvador: UCCV — FBC — COPPE/UFRJ.

SHNEIDERMAN, B. (1998). Designing the User Interface: strategies for effective HumanComputerInteraction. California: Addison Wesley, 3d ed.

SULliVAN, P. (1989). Beyond a Narrow Conception of Usability Testing. IEEE Transactions on Professional Communications, 32 (4), 256-264.

SUTTON, S. M., HEIMBIGNER, D., OSTERWEIL, L. J. (1995). APPL/A: A Languege for Software Process Programming. ACM Transactions on Software Engineering and Metodology: 4 (3), 221- 286.

WENGER, M. J., SPYRIDAKIS, J. H. (1989). The Relevance of Reliability and Validity to Usability Testing. IEEE Transactions on Professional Communications, 32 (4), 265-27 1.

WREDE, 0. (1997). Mnemonics in graphic interfaces. Form Dikurs, Journal of Design and Design Theory, 2(I), 120-131.

\section{PERFIL ACADÉMICO E PROFISSIONAL DOS AUTORES:}

Hernane B. B. Pereira

- Bacharel em Desenho Industrial - 1992

- Especialista em Análise de Sistemas e Informática - 1993

- Doutorando em Software, UPC - 1997

- Professor do Departamento de Ciáncias Exatas (Área de Informática) da Universidade Estadual de Feira de Santana — Bahia — Brasil — 1993

- Linha de pesquisa: Usabilidade cm sistemas interativos multimídia para a formaçáo a distáncia

Endereço:

Calle Robreño 49304 —08014 — Barcelona — España

Tel.: +3493439-4124

e-mail’s: hernane.pereira@upcnet.upc.es, Pereira@uefs.br

Josep W Monguet Fierro

- Ingeniero Industrial — 1981 
- Doctor en Ingeniería Industrial — 1986

- Profesor Titular de la Universtat Polit6cnica de Catalunya - 1987

- Director de los estudios de multimedia de la UPC y de la Universitat Oberta de Catalunya — UOC

- Responsable del programa de doctorado de Ingeniería Multimedia

Dirección:

Av. Diagonal 647 Dept0 Expresión Gráfica e Ingeniería, planta 5 - 08028 — Barcelona — España Tel.: +3493401-6560

e-mail's: monguet@ege.upc.es 